\title{
DELINEATING THE DYNAMIC INTERACTION OF VEGETATION AND SOIL PROPERTIES IN CONTROLLING CUT SLOPE SOIL EROSION
}

\author{
HALIM, A. ${ }^{1}-$ YUSOFF, I. $^{1}-$ OSMAN, N..$^{2 *}$ MOHAMED, N. A. ${ }^{3}$ \\ ${ }^{I}$ Department of Geology, Faculty of Science, University of Malaya, 50603 Kuala Lumpur, \\ Malaysia \\ (phone: +60-37-967-7162; fax: +60-37-967-5149) \\ ${ }^{2}$ Institute of Biological Sciences, Faculty of Science, University of Malaya, 50603 Kuala \\ Lumpur, Malaysia \\ (phone: +60-37-967-4185; fax: +60-37-967-4178) \\ ${ }^{3}$ Institute of Mathematical Sciences, Faculty of Science, University of Malaya, 50603 Kuala \\ Lumpur, Malaysia \\ (phone: +60-37-967-4034; fax: +60-37-967-4143) \\ *Corresponding author \\ e-mail:normaniza@um.edu.my, phone: +60-37-967-4185; fax: +60-37-967-5149
}

(Received 13 $3^{\text {th }}$ Jan 2021; accepted $9^{\text {th }}$ Apr 2021)

\begin{abstract}
The exposed environment of the cut slope due to insufficient coverage and changes in soil properties is greatly accelerating the occurrence of soil erosion. While revegetation is an alternative tool to mitigate soil erosion and provide a long-term solution for slope stability problems; the integration of vegetation and soil properties into slope erosion control, remains a challenge due to variation in plant types and site-specific slope conditions. Thus, in this study, three experimental plots were set up on the eroded cut slope: bare (control), less dense, and dense. To evaluate the interaction between vegetation and soil properties in mitigating soil erosion, the vegetated plots were grown with potential pioneers, namely Lantana camara, Melastoma malabathricum, and Bauhinia purpurea. After a two-year observation, the dense plot recorded the highest increment in soil total porosity and hydraulic conductivity by $45.8 \%$ and $73.8 \%$, respectively, thus enhancing the infiltration capacity of the slope soil and reducing the erosion rate between 10 to $15 \mathrm{t} \mathrm{h}^{-1}$ year $^{-1}$. Furthermore, L. camara in dense plot recorded the highest plant growth performance, followed by M. malabathricum, and this verifies their potential as good slope pioneers. Meanwhile, porosity, fungal/bacterial ratio, respiration, organic matter, and shoot hydraulic conductance were identified as significant parameters relevant to control erosion. In conclusion, the positive vegetation-soil interaction has shed light on slope stability, plant productivity, and most importantly erosion resistance.
\end{abstract}

Keywords: slope stability, soil loss, vegetation cover, slope revegetation, vegetation-soil interaction

\section{Introduction}

The cutting of slope faces to facilitate infrastructure development such as foundation and highway construction has resulted the exposure of rock surfaces to the weathering process and soil formation. As a result of ineffective maintenance and protection, the balance of soil hydrological networks is severely disturbed, and this leads to poor soil structure and susceptibility to soil erosion and slope failure. Moreover, hydrological and geotechnical processes within this degraded slope landscape is a serious concern as they depend on climate and geological conditions, topography, hydro-geotechnical properties, permeable interfaces, the type of surface cover, and human intervention (Huat et al., 2008; Sorbino and Nicotera, 2013; Rahman and Mapjabil, 2017). 
Furthermore, due to high seasonal precipitation in tropical regions, the oversupply of water flow into slope soils during intense or prolonged rainfall may overwhelm the soil infiltration rate, and this decreases the matrix suction and soil shear strength in addition to causing surface flow due to saturation excess (Ismail et al., 2018; Zhen-li, 2016). Consequently, these effects would further imperil the hydrological system of the slope, anticipating the increase in erosion and slope instability (Tang et al., 2018).

As one of the important slope management practices, revegetation is a feasible approach to ameliorating the function of the soil-plant complex system and improving slope stability. In general, the contributions of vegetation in enhancing slope stability and resilience can be divided into mechanical and hydrological. Firstly, through mechanical reinforcement, the vegetation root systems may increase the soil shear strength by root anchorage to improve cohesion, while the root architecture provides high resistance to prevent soil movement (Pollen, 2007; White et al., 2013; Saifuddin and Osman, 2014; Leung et al., 2018). Secondly, hydrological reinforcement through transpiration-induced matric is also deemed essential for slope hydrology and stability (Garg et al., 2015; Smethurst et al., 2015).

Notwithstanding, in some cases, vegetation on the slope can be detrimental to stability since its mere presence does not directly translate to the significant mitigation of slope problems. Since each slope has its own geological condition, the factors influencing slope stability can be very complex and require individual attention. For example, vegetation provides better volumetric retention compared to the bare slope; however, the physical properties and depth of the soil may exhibit greater influence than vegetation (VanWoert et al., 2005). Although vegetation can lower the soil moisture via interception and evapotranspiration (Halim and Normaniza, 2015; Keim and Skaugset, 2003), the effects might be adverse and subject to increase soil infiltration and permeability during intense rainfall (Coppin and Richards, 1990). Therefore, the consideration of specific plant types/species for the slope area has become a great emphasis in line with revegetation efforts.

Native species are the best candidates for the potential long-term solution towards stability and restoration; however, not all species are suitable for this practice. Furthermore, previous studies have also revealed that the practice of monoculture system, which focuses on the desirable characteristics of a single species, had caused soil depletion, expedited soil erosion, and adversely affected soil nutrient content (Moghaddam, 2014; Dislich et al., 2017). Hence, a mixed-culture system with high plant species is suggested as an alternative for slope revegetation management as it is more productive than monoculture (Zhang et al., 2012; Pretzsch and Schütze, 2016; Liu et al., 2018). The right combination of potential species can highly resist the harsh environment, maximize the soil nutrient cycling, increase carbon storage, and ultimately reduce the risks of soil erosion (Nerlich et al., 2013; Zhao et al., 2017).

In sum, the primary components of soil formation such as climate, parent material, and terrain landscape that compose the basic properties of soil are beyond the influence of management. Yet, biotic and abiotic factors are good targets of soil management, especially on the eroded cut slope area. Although vegetation on the cut slope sounds possible, it is a complex process and unfavourable soil conditions can make its introduction more challenging. Hence, the objectives of this study are to critically evaluate the interaction between vegetation and soil properties against soil erosion and to highlight the relevant parameters regulating slope processes at the plant-soilatmosphere interface in the context of erosion occurrences. 


\section{Materials and methods}

\section{Description of the study area}

The study site is located at Guthrie Corridor Expressway, Selangor, Malaysia

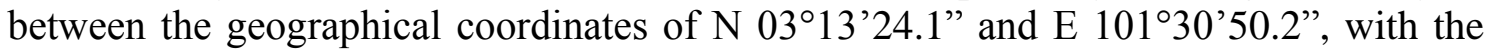
slope gradient ranging from $26^{\circ}$ to $35^{\circ}$ (Fig. 1). Briefly, the area lies within the geological formation of Kenny Hill, which comprises low-grade metasedimentary rocks, while the weathering grade of the study area was classified as grade III to IV. This variation from partially to highly weathered materials shows a mix-ground behavior and partly decomposed rock mass. While the weathered materials of the surface zone were interpreted as sandy clay loam, the major mineral identified in the study area was quartz and the chemical composition mainly contained silicon oxide $\left(\mathrm{SiO}_{2}\right)$ and aluminum oxide $\left(\mathrm{Al}_{2} \mathrm{O}_{3}\right)$ with $62.7 \%$ and $15.2 \%$, respectively.

The soil $\mathrm{pH}$ was moderate to slightly acidic, ranging from 3.78 to 5.37. Although the presence of aluminum oxide $\left(\mathrm{Al}_{2} \mathrm{O}_{3}\right)$ was harmless in the soil, the low-pH condition, however, could solubilize $\mathrm{Al}$ into $\mathrm{Al}^{3+}$ that severely impairs plant growth and leads to other nutrient deficiencies (Bojórquez-Quintal et al., 2017; Rahman et al., 2018) and vulnerability to soil erosion. The sheet and gully erosions were also found in the study area as a result of runoff formation. The annual average precipitation of the study area was $2114.5 \mathrm{~mm}$ with average temperature from 25 to $33{ }^{\circ} \mathrm{C}$, while the maximum Photosynthetically Active Radiation (PAR) recorded at the study site was $2100 \mathrm{mE} \mathrm{m}^{-2}$ $\mathrm{s}^{-1}$, with relative humidity between $60 \%$ and $75 \%$.

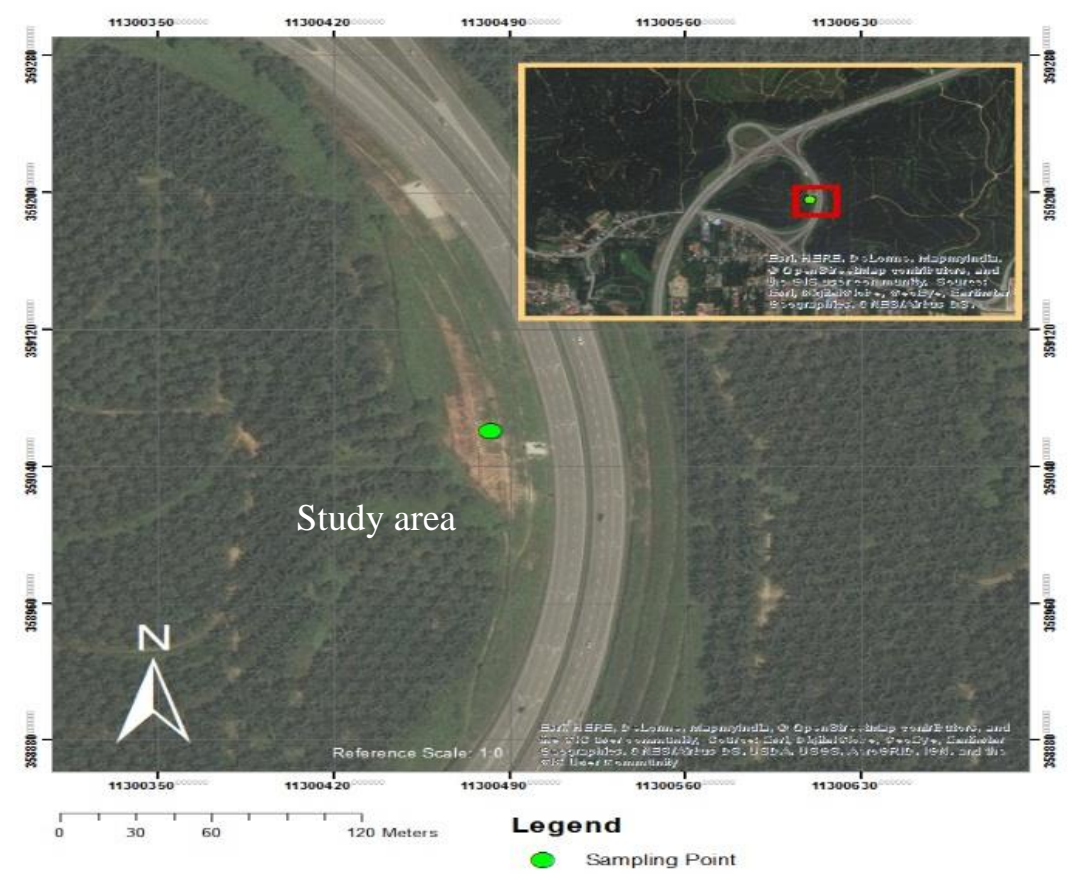

Figure 1. Location of the study area at the Guthrie Corridor Expressway (GCE), Selangor, Malaysia

\section{Experimental set-up}

Three experimental plots were set up on the rill-gully areas and assigned to three different vegetation coverages: bare (control), less dense (50\% of plant coverage), and 
dense ( $80 \%$ of plant coverage), each with $8 \mathrm{~m} \times 8 \mathrm{~m}$ in size (Fig. 2; Table 1). These vegetation densities suitably allow for interception $(\geq 95 \%)$ of the available Photosynthetically Active Radiation (PAR) for plant growth whilst promoting the establishment of new species (successors). Three potential slope plants were selected in this study, namely Lantana camara, Melastoma malabathricum, and Bauhinia purpurea (Halim and Normaniza, 2015; Saifuddin et al., 2016; Normaniza et al., 2018). These plants were transplanted onto slope using a Microclimate Plant Propagation Technique with modified soil depth (Osman and Barakbah, 2011) and they grew without any management practices throughout the experimental plots.

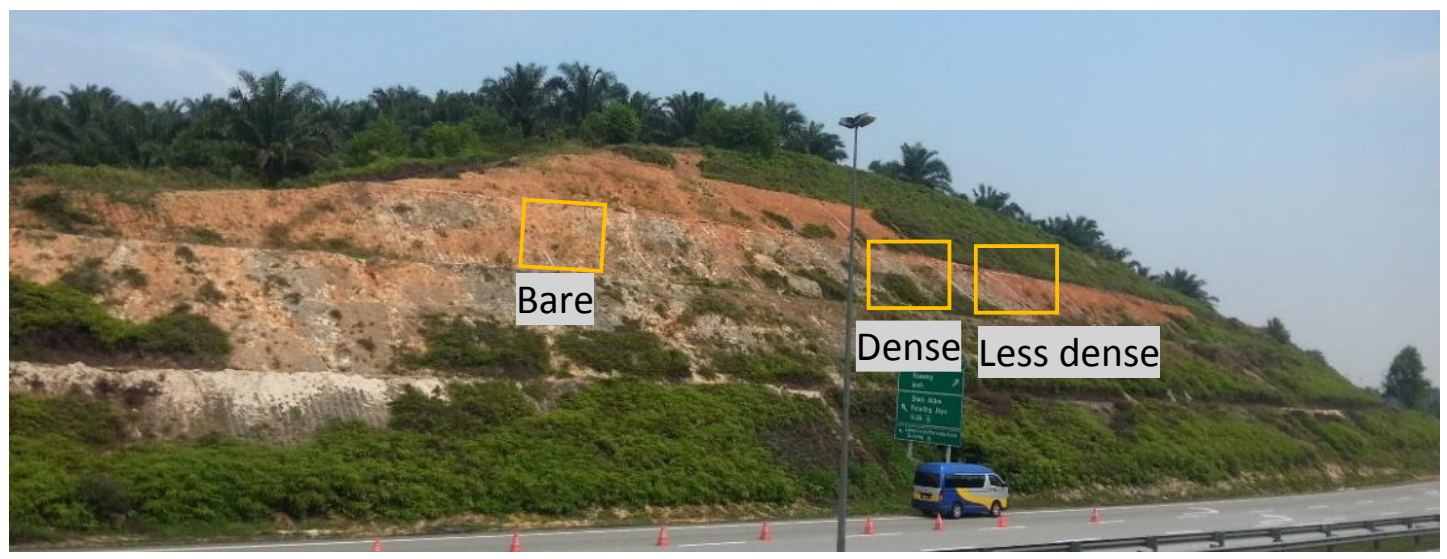

Figure 2. Experimental plots located on the third berm of the slope. From the left: bare plot $(B)$, dense plot $(D)$, and less dense plot $(L D)$

Table 1. Basic information on the studied plots

\begin{tabular}{c|c|c|c|c|c}
\hline Plot & $\begin{array}{c}\text { Slope angle } \\
(\%)\end{array}$ & $\begin{array}{c}\text { Elevation } \\
(\mathbf{m})\end{array}$ & $\begin{array}{c}\text { Plant } \\
\text { density } \\
\left(\mathbf{p l a n t} / \mathbf{m}^{2}\right)\end{array}$ & $\begin{array}{c}\text { Initial } \\
\text { vegetative } \\
\text { coverage }(\%)\end{array}$ & $\begin{array}{c}\text { Number of plants/species } \\
\text { ratio }(\text { L. camara }: \boldsymbol{M} \text {. } \\
\text { malabathricum }: \boldsymbol{B} . \\
\text { purpurea }\end{array}$ \\
\hline Control (C) & 53 & 63.5 & 0 & 0 & 0 \\
Less dense (LD) & 55 & 64.1 & 0.5 & 50 & $32-11: 10: 11$ \\
Dense (D) & 57 & 64.5 & 0.81 & 80 & $52-17: 17: 18$ \\
\hline
\end{tabular}

\section{Data measurement}

\section{Soil properties}

Laboratory analysis - total porosity, soil organic matter, and organic carbon

The soil samples in this study were collected using a metal auger (Edelman, Eijkelkamp, The Netherlands) up to $1 \mathrm{~m}$ in depth. Briefly, the soil samples were taken randomly from each plot with seven-point locations by traveling in a zigzag pattern, and they were taken every six months for two years. Meanwhile, the samples within the individual core sample were further homogenized by hand mixing, stored in polythene bags, and transported to the laboratory for processing. To determine the total porosity, the soil samples were then oven-dried at $105^{\circ} \mathrm{C}$ for three days and calculated as follows: 
where particle density $=2.65 \mathrm{~g} \mathrm{~cm}^{-3}$.

$$
\text { Bulk density }=\frac{\text { oven-dry weight of soil }(g)}{\text { Volume of soil core }(\mathrm{cm} 3)}
$$

While the soil organic matter was determined using the loss on ignition (LOI) method (Buurman et al., 1996), the total organic carbon, on the other hand, was determined using Walkley and Black's (1934) method.

\section{Field investigation - soil respiration, moisture content, and hydraulic conductivity}

To measure the respiration rate and moisture content, an in-situ measurement was randomly taken every six months for two years from each plot with seven-point locations by traveling in a zigzag pattern. The soil respiration rate was measured via the closed respiration chamber system (EGM- $4 \mathrm{CO}_{2}$, PP Systems, USA), while the soil moisture content was measured using portable Delta-T soil moisture (HH2 Moisture Meter, Delta -T Devices Ltd., England) installed at a depth of $5 \mathrm{~cm}$ from the soil surface, both between 11:30 and 12:30.

On the other hand, three holes were cored at each plot with $1 \mathrm{~m}$ in depth and $11.5 \mathrm{~cm}$ in diameter for the measurement of soil hydraulic conductivity $(\mathrm{K})$, which was performed using the Inverted Auger-Hole Method (Van Hoorn, 1979). This measurement was consistently taken during the third day after rain, between 11:30 and 12:30 with a PAR ranging from $1500-2100 \mu \mathrm{E} \mathrm{m}^{-2} \mathrm{~s}^{-1}$. Additionally, Gerlach's sampling field method (Gerlach, 1967) was also used to determine the soil erosion rate, and the experimental plots were further enclosed with wooden barriers about $25 \mathrm{~cm}$ in height in order to observe the influence of coverage treatment on soil loss. Finally, the eroded soils were collected, air-dried, and weighed accordingly.

\section{Soil microbe (fungal/bacteria ratio)}

The soil microbe enumeration of each treatment plot was analyzed every six months for two years and the soil samples were collected from seven-point locations by traveling in a zigzag pattern at the depths of 0-25 cm, 26-50 cm, and 51-100 cm using a sterile spatula. The samples were further mixed into homogenous samples, placed in sterile plastic containers, and transported to the laboratory for further processing. $1 \mathrm{~g}$ of soil was serially diluted ten-fold in quarter strength Ringer's solution, whereas $100 \mu 1$ of soil suspension was spread onto agar plates in triplicates. Bacteria and fungi were also isolated on soil extract agar and potato dextrose agar media, respectively. The inoculated nutrient agar plates were further incubated for 3 to 7 days at $28{ }^{\circ} \mathrm{C}$, while the observed bacteria and fungi colonies were enumerated as colony-forming units per gram of soil (cfu/g).

\section{Vegetation measurement}

Photosynthetic rate, transpiration rate, and leaf water potential

Photosynthetic rate and transpiration rate were measured in three fully expanded leaves per plant with replicated three plants per species, per plot, and at a six-month interval. These parameters were measured using a portable photosynthesis system 
(Li6400XT, LICOR, USA) in an open system mode, between 10:30 and 12:30. Ambient $\mathrm{CO}_{2}(\mathrm{Ca})$ was set at $400 \mathrm{ppm}$, whereas the temperature and Photosynthetically Active Radiation (PAR) were set according to the ambience and 'track PAR out' in the leaf chamber, respectively.

Root hydraulic conductance, shoot hydraulic conductance, and diurnal leaf water potential

To avoid plant destruction and susceptibility to soil detachment, root $(\mathrm{Kr})$ and shoot (Ks) hydraulic conductance were measured in situ for each species in both plots with a High-Pressure Flow Meter (HPFM) (Dynamax Inc., Houston, USA) after two years of observation. The measurements were taken between 11:30 and 12:30 at (PAR), ranging from 1500-2100 $\mu \mathrm{E} \mathrm{m}^{-2} \mathrm{~s}^{-1}$ and at ambient temperature in order to minimize the potential diurnal periodicity of hydraulic conductance (Tyree et al., 1995). Meanwhile, diurnal leaf water potential was measured using a Pressure Chamber (Model 1515D, PMS Instrument Company, USA) at 08:00, 10:00, 12:00, 14:00, 16:00, and 17:00, respectively.

\section{Statistical analysis}

A one-way analysis of variance (ANOVA) was performed to assess the effects of vegetation coverage on soil properties and plant physiological properties by using the SPSS software (Version 20, IBM, USA). While the estimation of control parameters that affects the variation in hydrological performance at different vegetation coverages was determined using linear mixed models (LMM) in R software. The 'lme4' package (Bates et al., 2015) was used to fit the model in R.

\section{Results and discussion}

\section{The influence of vegetation on soil structural stability}

The dense plot (D) shows notable effects per the increase in total porosity by $45.8 \%$ in two years, which is significantly higher than the less dense (LD) and control (C) plots with $14.34 \%$ and $90.63 \%$, respectively (Fig. 3). However, no increment of total porosity was found in bare soil (control plot). Furthermore, during the initial study period, the coarse and poorly structured sandy soil contributed to lower porosity, thereby resulting in poorly drained soil and lower soil ability to hold water (Libohova et al., 2018; Igor et al., 2020). After two years of revegetation, the higher vegetation coverage reduces the natural soil compaction and enhances the generation of macropores and channels by root penetration, thus improving the physical structure of the slope soil in order to resist erosion (Fageria and Stone, 2006).

As plants grow well, organic matter at the topsoil increases as well. In this study, organic matter content increased consistently with time in both revegetated plots. At the end of the experiment, organic matter content was drastically enhanced, and it further increased nearly fourfold as can be seen in the dense plot (D) (Fig. 4). The high number of plants in the dense plot (D) leads to a higher interception and high surface litter reserves and decomposition, thus providing a remarkable effect on the organic matter accumulation (Middleton, 2020). As a result, organic matter facilitates soil aggregation and subsequently conveys water more efficiently whilst enhancing soil infiltration (Yang and Zhang, 2011). 


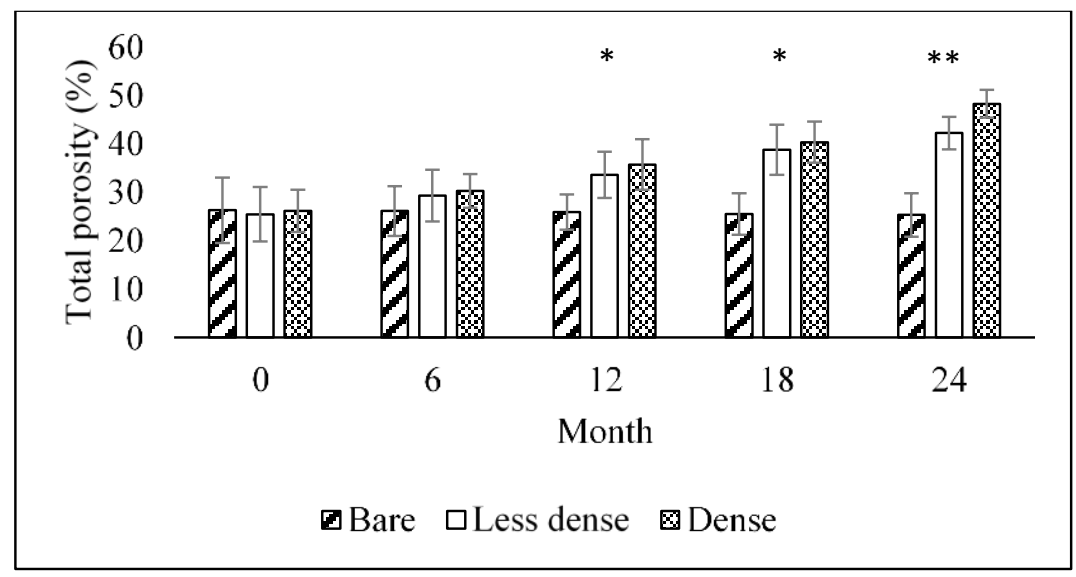

Figure 3. Means total porosity of the three experimental plots. Vertical bars indicate the standard deviation, whereas $*$ and $* *$ denote significant differences between plots at $p \leq 0.05$ and $p \leq 0.001$, respectively $(n=21)$

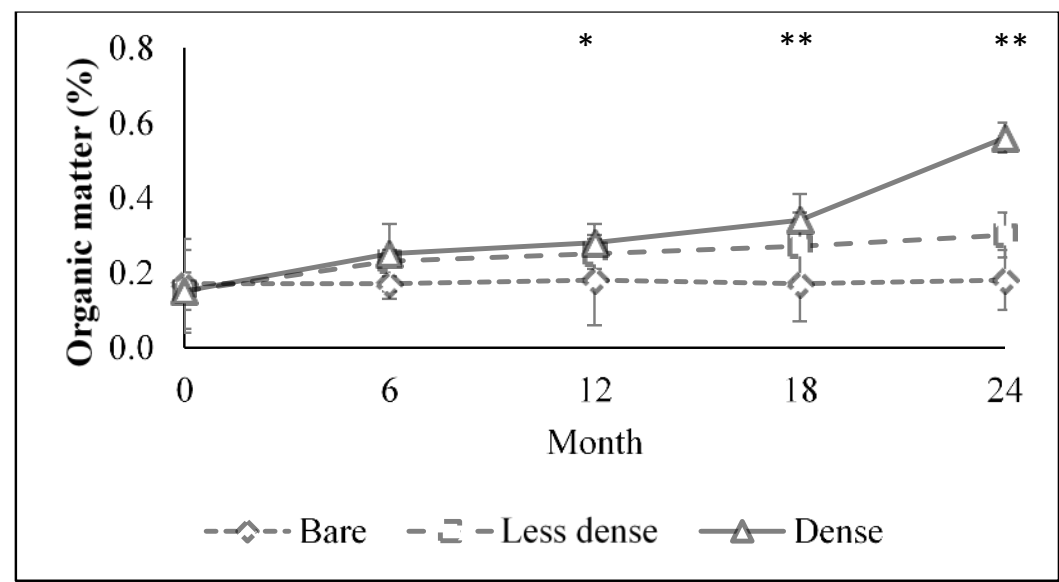

Figure 4. Means organic matter of the three experimental plots. Vertical bars indicate the standard deviation, whereas $*$ and $* *$ denote significant differences between plots at $p \leq 0.05$ and $p \leq 0.001$, respectively $(n=21)$

\section{The contributions of vegetation to soil hydrological properties}

Within two years of observation, the soil hydraulic conductivity showed an increasing trend with vegetation coverage. While the dense plot (D) showed a positive increase in the hydraulic conductivity (Ks) value by $73.8 \%$ and followed by the less dense plot with $30.85 \%$ (Fig. 5), the control plot, however, demonstrated a fluctuation trend and it was slightly dropping towards the end of the experiment. Apart from organic matter accumulation, the plant roots may also enhance and promote soil hydraulic conductivity by forming pore networks, aiding in soil water conservation, and diminishing the slope runoffs (Wang et al., 2017; Lange et al., 2009; Neumann and Cardon, 2012; Kalhoro et al., 2017).

Furthermore, in terms of soil moisture, the dense plot (D) showed a higher value compared to less dense (LD) and control (C) plots with $27.44 \%$ and $68.37 \%$, respectively (Fig. 6). Nevertheless, no changes were observed in the moisture content in all treatments during the 0,6 th, and 12 th months. This suggests that the rainfall factor is 
most influential than the slope pioneer effects. Additionally, the right vegetation density might have also influenced the higher moisture content in the dense (D) plot by reducing evaporative losses through plant canopy and holding both horizontal and vertical water flow in the soil via root distribution (Asbjornsen et al., 2011; Aalto et al., 2013). In fact, the presence of vegetation might likewise increase soil water consumption, and this was verified in this study as the findings demonstrated that soil moisture had further increased water consumption as opposed to the bare soil. Subsequently, this condition could avoid soil water stress and mitigate the impact of soil drying in the subsurface (Oliveira et al., 2005; Bayala and Prieto, 2019).

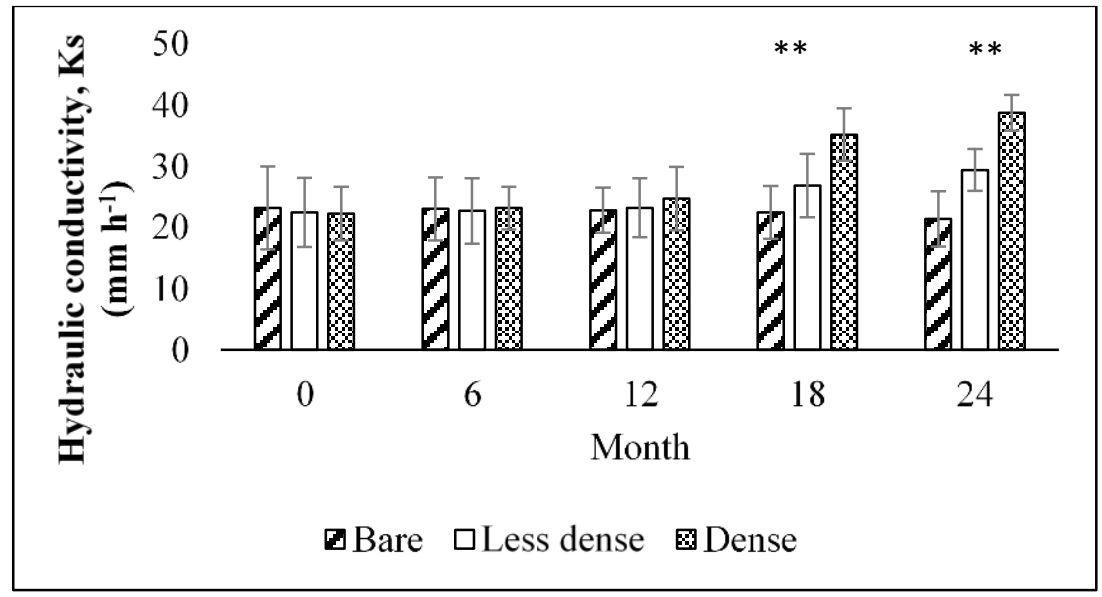

Figure 5. Means hydraulic conductivity of the three experimental plots. Vertical bars indicate the standard deviation, whereas $*$ and $* *$ denote significant differences between plots at $p \leq 0.05$ and $p \leq 0.001$, respectively $(n=9)$

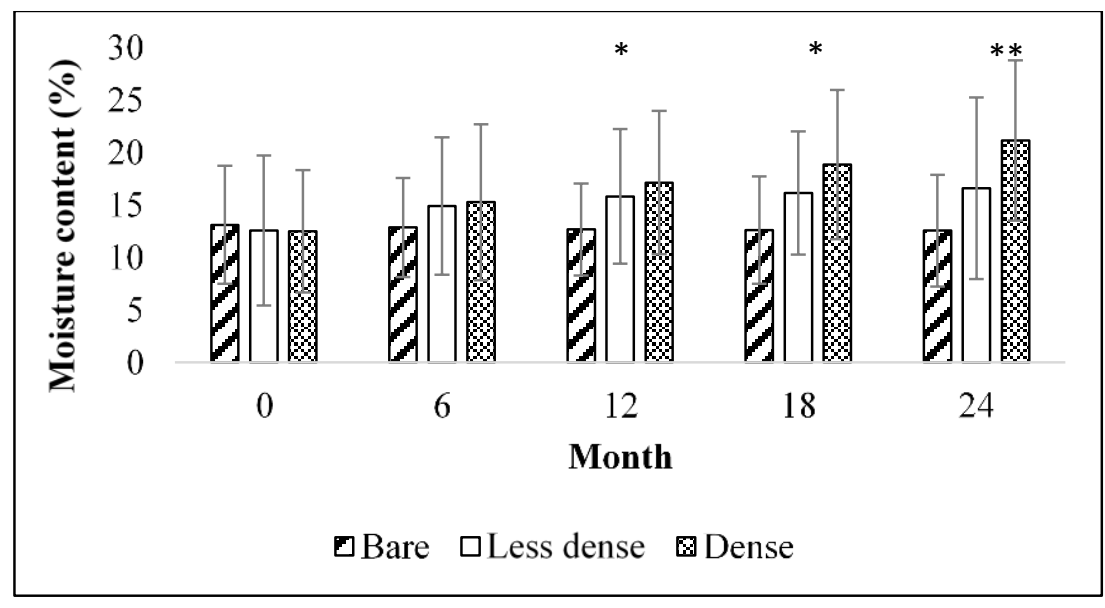

Figure 6. Means moisture content of the three experimental plots. Vertical bars indicate the standard deviation, whereas $*$ and $* *$ denote significant differences between plots at $p \leq 0.05$ and $p \leq 0.001$, respectively $(n=21)$

\section{The impact of vegetation on soil carbon sequestration and quality}

The results exhibited significant differences in the total organic carbon between treatments (Fig. 7). Evidently, both vegetated plots have significantly higher total 
organic carbon than the control plot; hence, this improves the soil fertility of the slope. The total organic carbon value was also estimated to increase six-fold within two years in the dense plot (D) and four-fold (400\%) in the less dense plot (LD). These findings suggest that high litter decomposition corresponds to a high concentration of organic carbon, thus accelerating the transport of organic carbon to deep soil layers and increasing soil carbon stocks (Dawud et al., 2016; Zhao et al., 2019). Besides, the mixed-culture system in this study had also produced a higher quantity and quality of litters, resulting in a remarkable soil carbon stock in the study area.

Due to high organic carbon concentration, the soil respiration rate was greater than during the early study period (Fig. 8). The increased respiration rate in the dense plot (D) was more than twice compared to 6 months after transplanting $(212.75 \%)$, while the less dense plot (LD) recorded about $175 \%$ increment. The increase in the respiration rate might be due to decomposition activities of plant litters; hence, this shows a good sign of microbial abundance in soil and the development of the $\mathrm{C}$ cycle in terrestrial ecosystems (Adachi et al., 2006).

Overall, the initial datasets of both fungal and bacterial abundances were inconsistent between all treatments; thus, the F/B ratio fluctuated likewise. As illustrated in Figure 9, fungal and bacterial abundances as well as the F/B ratio were affected by vegetation establishment. After two years of observation, the $\mathrm{F} / \mathrm{B}$ ratio tremendously decreased in all treatments, and the dense plot (D) exhibited a higher F/B ratio value compared to control (C) and less dense (LD) plots with $33.33 \%$ and $100 \%$, respectively. Generally, the F/B ratio has been extensively used in soil ecology, particularly in the context of land management (Strickland and Rousk, 2010). While the cause of the differences in the F/B ratio in the studied plots is not entirely clear, they might be attributed to subtle differences in the total aboveground plant coverage. As such, the higher number of plants in the dense plot (D) could enhance the F/B ratio through ecological complementarity effects such as a higher supply of resources for microorganisms (Lange et al., 2014). The microbial networks thereupon contribute to the soil-root bonding, transfer of lifted water, and nutrient sharing between plant species, thus enhancing plant growth and soil stability in the study area (Prieto et al., 2016; Montesinos-Navarro et al., 2019).

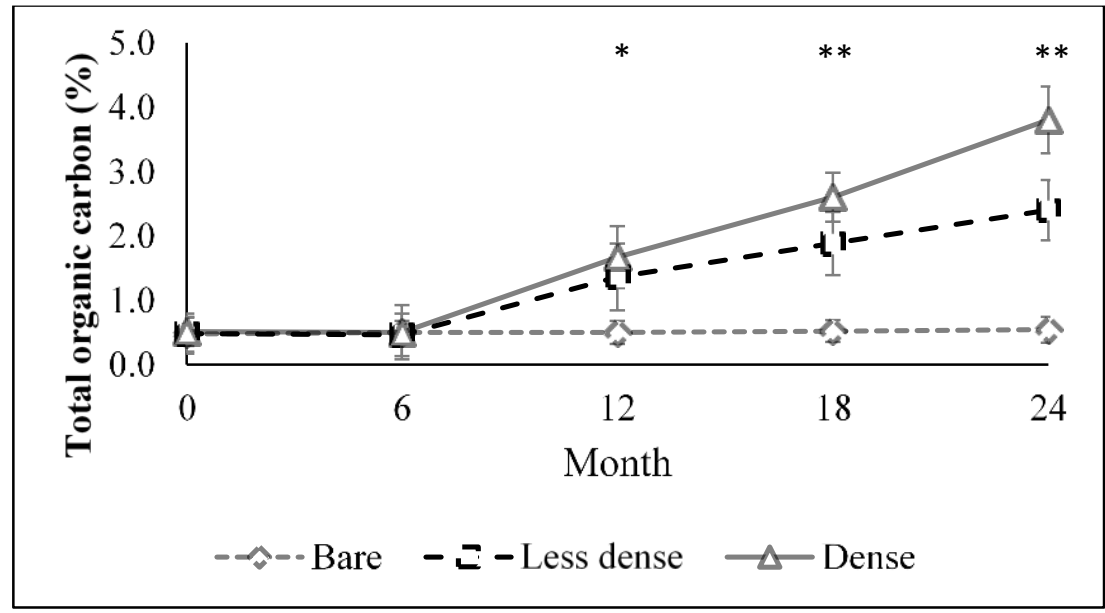

Figure 7. Means total organic carbon of the three experimental plots. Vertical bars indicate the standard deviation, whereas $*$ and $* *$ denote significant differences between plots at $p \leq 0.05$ and $p \leq 0.001$, respectively $(n=21)$ 


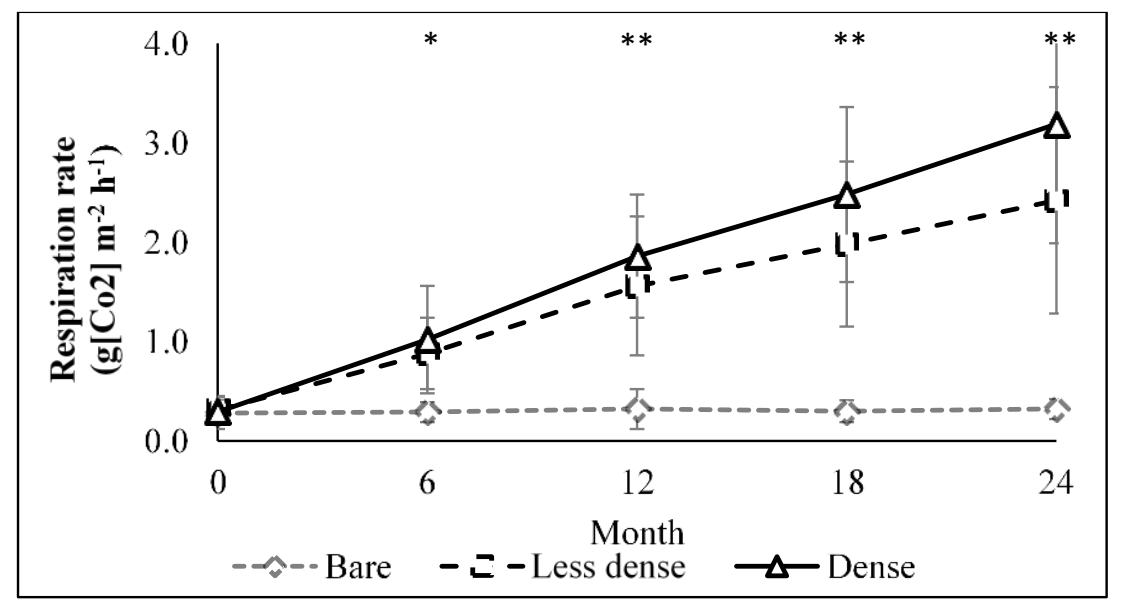

Figure 8. Means respiration rate of the three experimental plots. Vertical bars indicate the standard deviation, whereas $*$ and $* *$ denote significant differences between plots at $p \leq 0.05$ and $p \leq 0.001$, respectively $(n=21)$

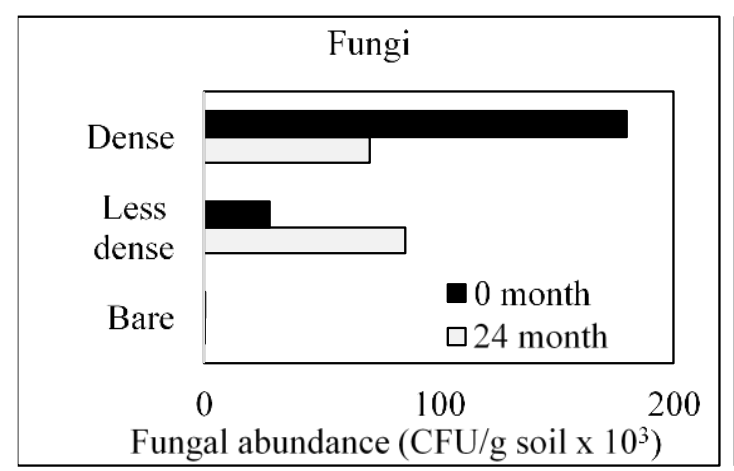

(a)

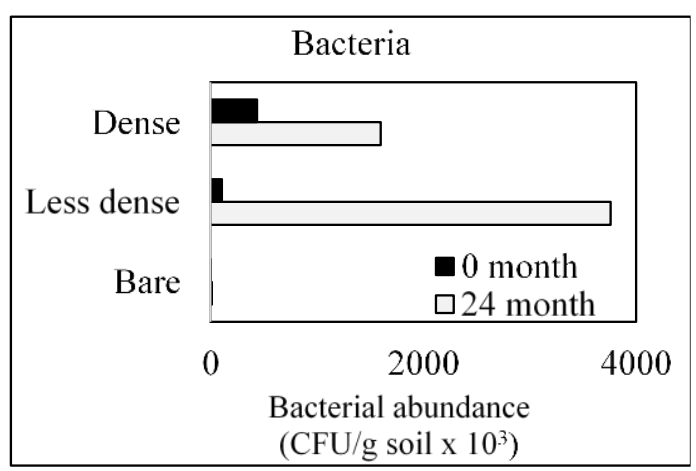

(b)

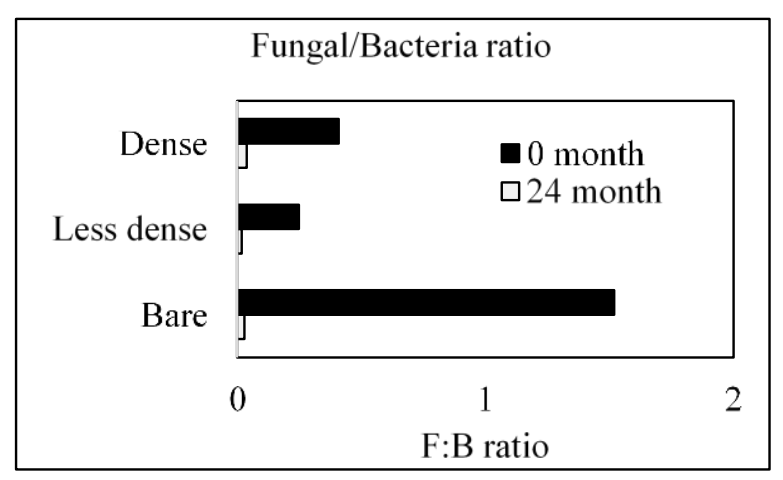

(c)

Figure 9. (a) Fungal abundance; (b) bacterial abundance; and (c) the fungal:bacterial ratio, $F / B$ of the three experimental plots

\section{Growth performance of slope pioneers}

Vegetation that induced changes in slope soil conditions has further resulted in reciprocal effects that influence the growth performance of the species in this study. For instance, the increase in soil quality and fertility by the dense, mixed-cultured plant community reportedly has a positive influence on the individual plant growth 
performance. Further, in terms of photosynthetic rate $(\mathrm{A})$ and transpiration rate $(\mathrm{E})$, it was revealed that L. camara exhibited the highest increment in both treatments, followed by $M$. malabathricum and B. purpurea. Similarly, to compare between plots, the total photosynthetic increment rate of L. camara in the dense plot (D) was also higher with $40.79 \%$ than the less dense plot (LD) (Fig. 10).

L. camara's sun tolerant feature and its high adaptability to the harsh environment enable this species to have greater growth performance wherein it exhibits the highest value of stomata openings and subsequently induces light utilization efficiency in photosynthesis, transpiration, and biomass production (Sharma et al., 2005; Aoki et al., 2019). Meanwhile, M. malabathricum was the second prominent species in this study. This species is highly tolerant and accumulates $\mathrm{Al}$ in soil, enabling them to survive and increase their growth performance (Watanabe et al., 2006). Unfortunately, the high soil acidity and $\mathrm{Al}$ content reduced the growth performance of $B$. purpurea, hence its decline in dry weight, nutrient uptake, and lower growth performance (Watanabe et al., 2005). In short, although high vegetation coverage is expected to thrive in the highly competitive plant community, the current research findings verify the prominent contribution of the species in this study as outstanding pioneers on the slopes.

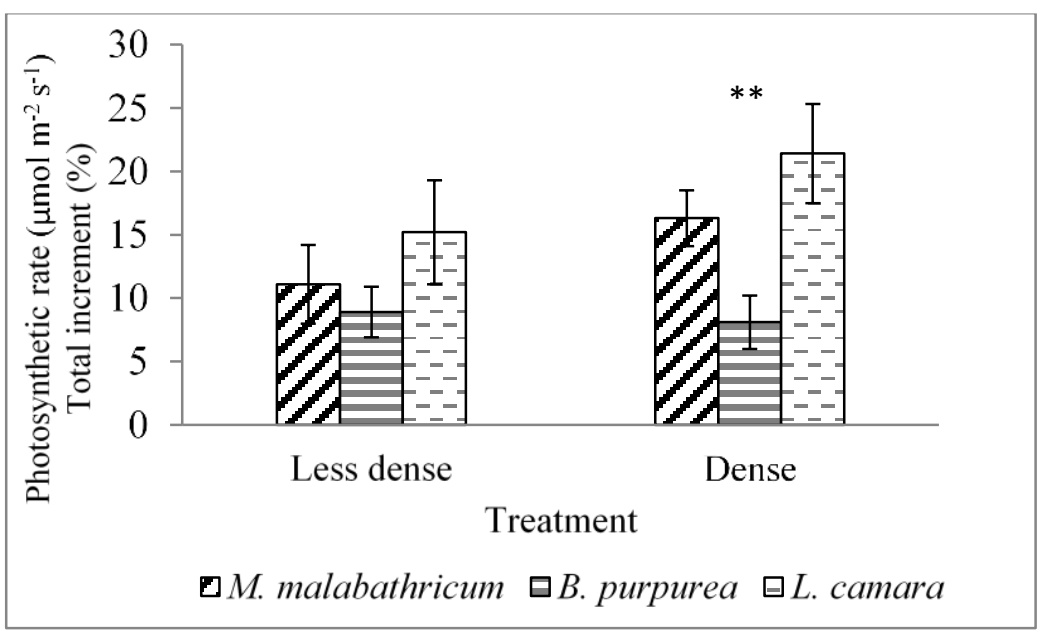

(a)

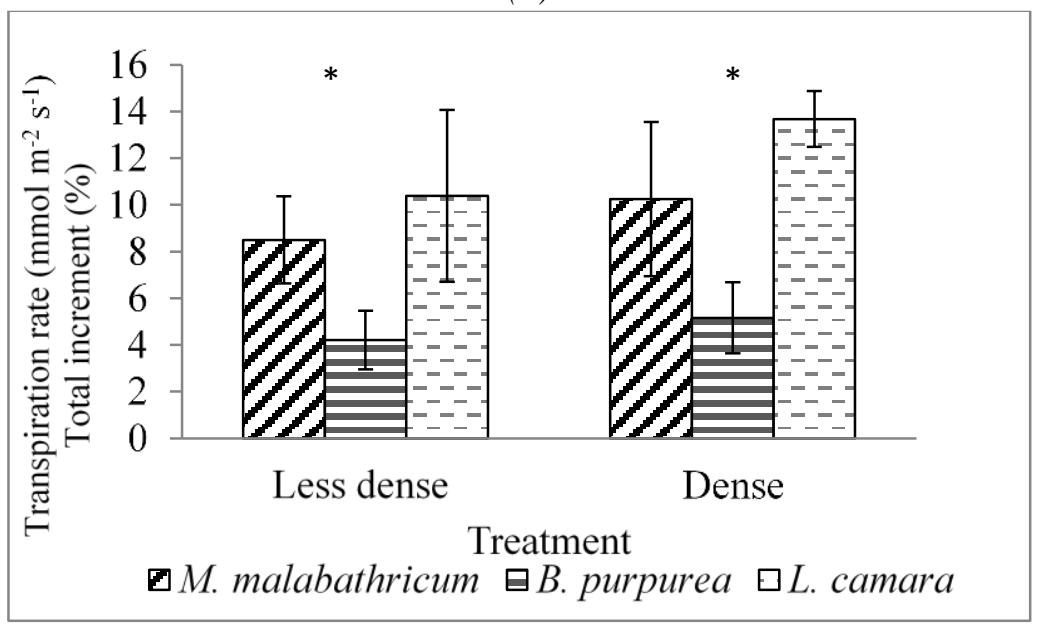

(b)

Figure 10. Total increment of (a) photosynthetic rate and (b) transpiration rate of the species studied at different vegetation coverages. Vertical bars indicate the standard deviation, whereas * and $* *$ denote significant differences between plots at $p \leq 0.05$ and $p \leq 0.001$, respectively $(n=27)$ 


\section{Plant water transport}

Several studies have revealed that the differences in the growth performance of various plant species affect their plant-soil-water relationship (Buxton et al., 2007). In this study, as vapor pressure deficit (VPD) increases, the diurnal leaf water potential decreases and shows a typical behavior, whereas the increase in transpiration is associated with a decrease in leaf water potential. On average, $L$. camara showed greater diurnal leaf water potential compared to M. malabathricum and B. purpurea (Fig. 11).

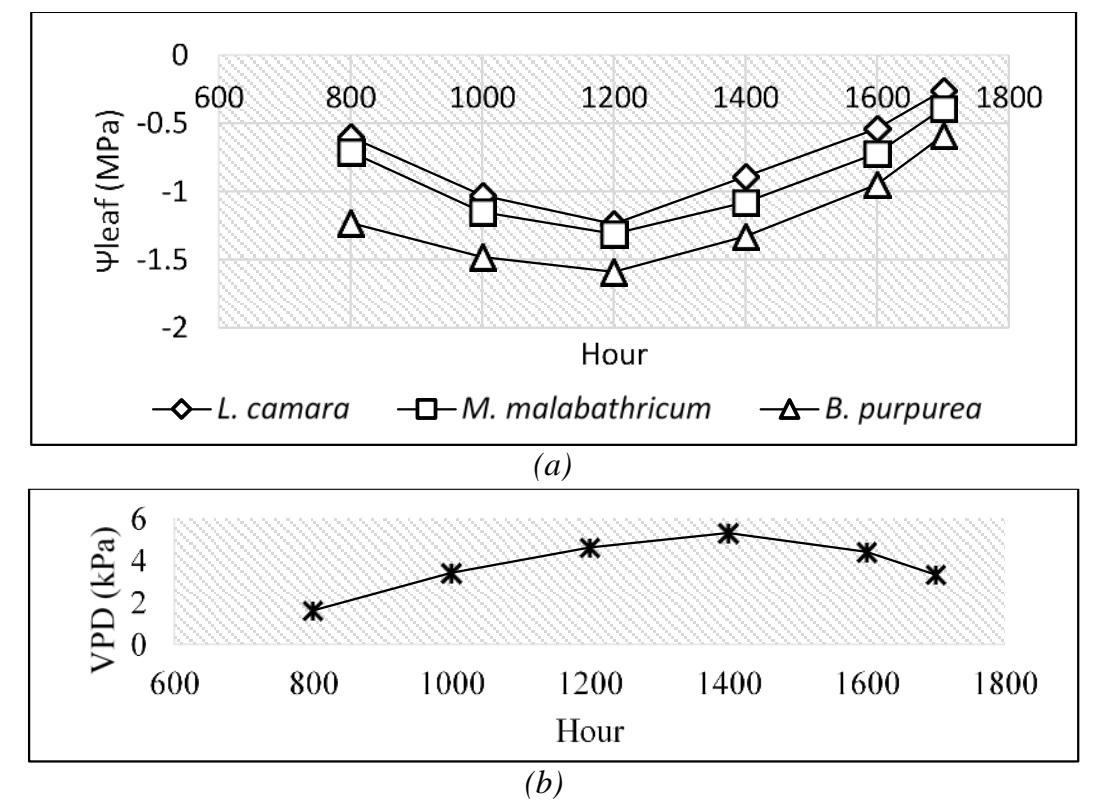

Figure 11. Diurnal variation of (a) leaf water potential and (b) vapor pressure deficit of each species

Apart from that, L. camara recorded the highest root hydraulic conductance ( $\mathrm{Kr}$ ) with $76.7 \%$, which increased trifold compared to M. malabathricum and B. purpurea (Fig. 12). However, M. malabathricum recorded the highest shoot hydraulic conductance (Ks) with $36.59 \%$ higher compared to L. camara. These results show the powerful regulatory mechanisms of each plant to modulate water transport [soil-plantatmosphere continuum (SPAC)] in response to atmospheric evaporative demand (Martínez-Vilalta et al., 2014). As such, this could be a strategy to reduce air bubble formation in the xylem to avoid cavitation since Ks is always equivalent to or lower than $\mathrm{Kr}$ for both $M$. malabathricum and L. camara. Taking all parameter performance into account, it can be deduced that $L$. camara has an outstanding growth rate performance even in the harsh environment, followed by M. Malabathricum and $B$. Purpurea (L. Camara > M. Malabathricum $>$ B. Purpurea).

\section{Soil erosion performance}

Given the most enhancement of soil parameters and plant functional traits over time in the revegetated dense (D) and less dense (LD) plots, the erosion rate is also expected to decline with the increase in vegetation coverages. After two years of experiment, the erosion rate shows significant differences between treatments (Fig. 13), with the dense plot (D) yielding significantly lower rates with $47.6 \%$ and $76.17 \%$ compared to the less 
dense (LD) and control (C) plots. Based on these findings, it can be deduced that the species in this study have successfully reflected the performance of plant canopies in interception capacity, thereby delaying the onset to run-off and reducing sediment transport (Zhao et al., 2019). In addition, high root branches of the shrubs and the combination of roots from the neighbouring plants (mixed-culture system) could further promote maximum resistance, and this explains the increased soil penetrability in the revegetated plots in this study (Osman and Barakbah, 2006; Guo et al., 2020) as well as the strengthened effects on the slope stability (Yildiz et al., 2018).

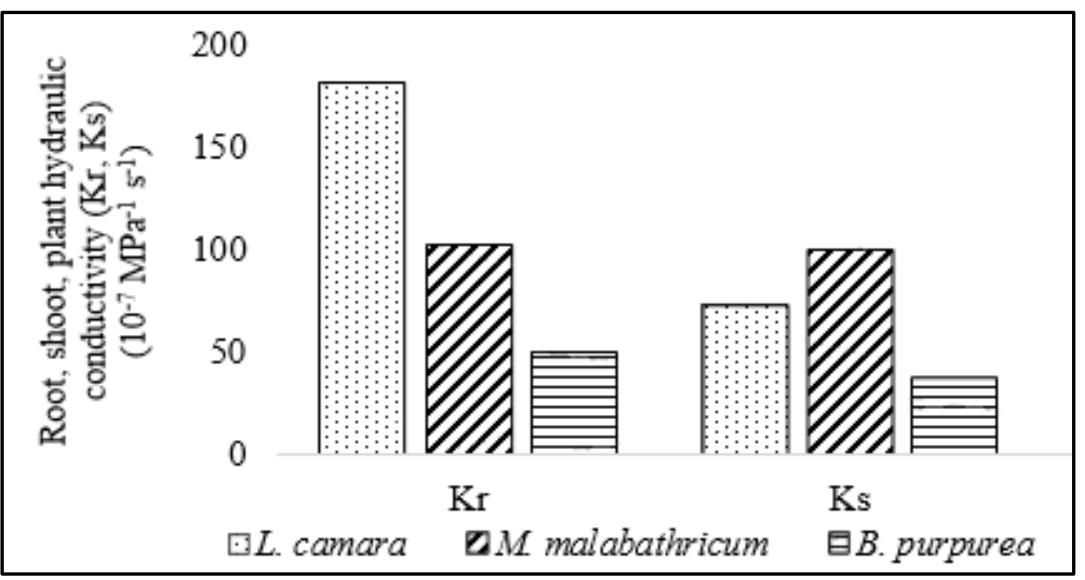

Figure 12. Root and shoot hydraulic conductance (Kr and $K s)$ of each species

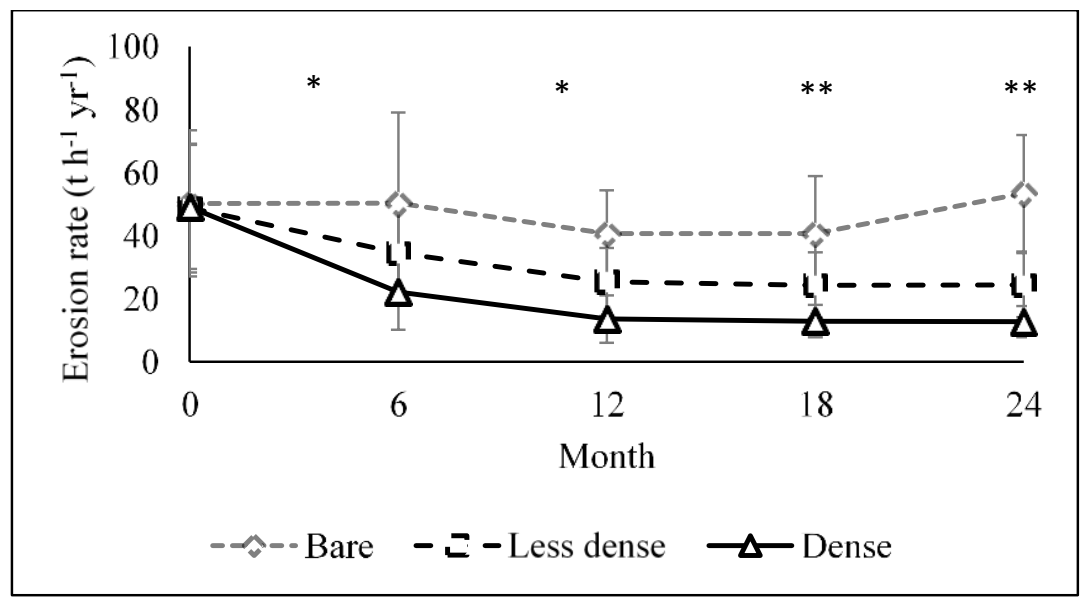

Figure 13. Means erosion rate of the three experimental plots. Vertical bars indicate the standard deviation, whereas $*$ and $* *$ denote significant differences between plots at $p \leq 0.05$ and $p \leq 0.001$, respectively $(n=9)$

\section{Which parameters are the most relevant in erosion control?}

Overall, the above results imply the influence of revegetation practice on the improvement of slope conditions in two ways, namely through changes in basic soil properties and through SPAC (soil-plant-atmosphere continuum). Thus, it can be inferred that the vegetation-soil processes are complex and clearly not conferred by a single parameter. 
Since this study mainly aims to alleviate slope erosion, the study, therefore, found that soil porosity, soil respiration rate, shoot hydraulic conductance, fungal/bacterial (F/B) ratio, and soil organic matter are relevant parameters for assessing the vegetationsoil performance of the areas with similar soil properties as the studied slope in combatting erosion (Table 2).

Table 2. List of significant relevant parameters of vegetation-soil interaction towards slope erosion performance

\begin{tabular}{c|c|c}
\hline Significant variable & P-value (5\%) & Confidence interval (97.5\%) \\
\hline Porosity & 0.00052 & $(-1.85544,-0.67769)$ \\
Respiration & 0.00516 & $(1.57946,6.64670)$ \\
Shoot hydraulic conductivity & 0.00608 & $(-1.80393,-0.40849)$ \\
Fungal/bacteria ratio & 0.01607 & $(1.33659,8.86063)$ \\
Organic matter & 0.00034 & $(21.57223,56.16040)$ \\
\hline
\end{tabular}

The high correlations between these parameters indeed reflected their inextricable associations and simultaneous occurrences in the study area. Hence, the inclusion of these relevant parameters into slope erosion study should be simplified, but they should also be able to practically and fully describe the vegetation-soil performance in alleviating erosion.

\section{Conclusion}

Overall, the results in this study have confirmed that erosion performance in the study area is associated with the dynamic interactions between the plant functional traits, soil parameters, and the microbial properties, which contributions differed simultaneously with vegetation coverages. While the dense and mixed-culture system of the selected slope pioneers exerted promising effects on soil components in the studied slope, the establishment of plants on the compacted and infertile sandy textured soils, on the other hand, has enhanced the soil infiltration via increased porosity, hydraulic conductivity, organic matter accumulation, improved carbon storage, and reduction in soil erosion. Moreover, the success of enhancing plant growth through the modulation of photosynthesis and water transport has clearly verified the potential of L. camara and $M$. malabathricum as good slope pioneers. Furthermore, in response to the vegetation of the cut-slope ecosystem, the relevant parameters identified in this study are expected to reflect the changes in soil properties and erosion processes more closely. Finally, the current study has the potential to be improved and expanded for further research; hence, the study recommends that since the identified key parameters in this study are specific to the investigated slope and the outputs might differ due to slope condition variations (e.g. parent material, topography, and microclimatic), the parameters should be expanded to a broader range of slope conditions such as variable slope angles and different plant types should be introduced to capture their involvement throughout the research.

Acknowledgements. This work was supported by the University of Malaya Research Grant (UMRGRP005A-13SUS \& RP005D-13SUS). The authors are also thankful to the Guthrie Corridor Expressway (GCE) for the opportunity to use their slope as the experimental site for this project. 


\section{REFERENCES}

[1] Aalto, J., le Roux, P. C., Luoto, M. (2013): Vegetation mediates soil temperature and moisture in arctic-alpine environments. - Arctic, Antarctic, and Alpine Research 45(4): 429-439.

[2] Adachi, M., Bekku, Y. S., Rashidah, W., Okuda, T., Koizumi, H. (2006): Differences in soil respiration between different tropical ecosystems. - Applied Soil Ecology 34(2-3): 258-265.

[3] Aoki, S., Toh, S., Nakamichi, N., Hayashi, Y., Wang, Y., Suzuki, T., ... Kinoshita, T. (2019): Regulation of stomatal opening and histone modification by photoperiod in Arabidopsis thaliana. - Scientific Reports 9(1): 1-9.

[4] Asbjornsen, H., Goldsmith, G. R., Alvarado-Barrientos, M. S., Rebel, K., Van Osch, F. P., Rietkerk, M., ... Gomez-Tagle, A. (2011): Ecohydrological advances and applications in plant-water relations research: a review. - Journal of Plant Ecology 4(1-2): 3-22.

[5] Bates, D., Maechler, M., Bolker, B., Walker, S., Christensen, R. H. B., Singmann, H., ... Bolker, M. B. (2015): Package 'Ime4'. - Convergence 12(1): 2.

[6] Bayala, J., Prieto, I. (2019): Water acquisition, sharing and redistribution by roots: applications to agroforestry systems. - Plant and Soil 1-12.

[7] Bojórquez-Quintal, E., Escalante-Magaña, C., Echevarría-Machado, I., Martínez-Estévez, M. (2017): Aluminum, a friend or foe of higher plants in acid soils. - Frontiers in Plant Science 8: 1767.

[8] Buurman, P., Van Lagen, B., Velthorst, E. J. (1996): Manual for Soil and Water Analysis. - Backhuys Publishers, Leiden.

[9] Buxton, K. N., Clearwater, M. J., Giles-Hansen, K., Hewett, E. W., Ferguson, I. B. (2007): Comparison of xylem sap mineral concentrations between kiwifruit shoot types using spittlebugs for non-destructive sampling of sap. - Functional Plant Biology 34(11): 1029-1037.

[10] Coppin, N. J., Richards, I. G. (1990): Use of Vegetation in Civil Engineering. Construction Industry Research and Information Association, London.

[11] Dawud, S. M., Raulund-Rasmussen, K., Domisch, T., Finér, L., Jaroszewicz, B., Vesterdal, L. (2016): Is tree species diversity or species identity the more important driver of soil carbon stocks, C/N ratio, and pH? - Ecosystems 19(4): 645-660.

[12] Dislich, C., Keyel, A. C., Salecker, J., Kisel, Y., Meyer, K. M., Auliya, M., ... Hess, B. (2017): A review of the ecosystem functions in oil palm plantations, using forests as a reference system. - Biological Reviews 92(3): 1539-1569.

[13] Fageria, N. K., Stone, L. F. (2006): Physical, chemical, and biological changes in the rhizosphere and nutrient availability. - Journal of Plant Nutrition 29(7): 1327-1356.

[14] Garg, A., Leung, A. K., Ng, C. W. W. (2015): Transpiration reduction and root distribution functions for a non-crop species Schefflera heptaphylla. - Catena 135: 78-82.

[15] Gerlach, T. (1967): Hillslope troughs for measuring sediment movement. - Revue de Geomorphologie Dynamique 17: 173.

[16] Guo, M. M., Wang, W. L., Kang, H. L., Yang, B., Li, J. M. (2020): Changes in soil properties and resistance to concentrated flow across a 25-year passive restoration chronosequence of grasslands on the Chinese Loess Plateau. - Restoration Ecology 28(1): 104-114.

[17] Halim, A., Normaniza, O. (2015): The effects of plant density of Melastoma malabathricum on the erosion rate of slope soil at different slope orientations. International Journal of Sediment Research 30(2): 131-141.

[18] Huat, B. B., Ali, F. H., Baker, D. H., Singh, H., Husaini, O. (2008): Landslides in Malaysia: Occurences, Assesment, Analyses and Remediation. - Penerbit Universiti, Putra, Malaysia.

[19] Igor, B., Leon Josip, T., Paulo, P. (2020): Agriculture management impacts on soil properties and hydrological response in Istria (Croatia). - Agronomy 10(2): 282. 
[20] Ismail, M. A. M., Hamzah, N. H., Min, N. S., Abidin, M. H. Z., Tajudin, S. A. A., Madun, A. (2018): Analysis of infiltration-suction response in unsaturated residual soil slope in Gelugor, Penang. - Journal of Physics: Conference Series, Volume 995, International Seminar on Mathematics and Physics in Sciences and Technology 2017 (ISMAP 2017) 28-29 October 2017, Hotel Katerina, Malaysia.

[21] Kalhoro, S. A., Xu, X., Chen, W., Hua, R., Raza, S., Ding, K. (2017): Effects of different land-use systems on soil aggregates: a case study of the Loess Plateau (Northern China). - Sustainability 9(8): 1349.

[22] Keim, R. F., Skaugset, A. E. (2003): Modelling effects of forest canopies on slope stability. - Hydrological Processes 17(7): 1457-1467.

[23] Lange, B., Lüscher, P., Germann, P. (2009): Significance of tree roots for preferential infiltration in stagnic soils. - Hydrology and Earth System Sciences 13(10): 1809-1821.

[24] Lange, M., Habekost, M., Eisenhauer, N., Roscher, C., Bessler, H., Engels, C., ... Gleixner, G. (2014): Biotic and abiotic properties mediating plant diversity effects on soil microbial communities in an experimental grassland. - PloS One 9(5).

[25] Leung, F., Yan, W., Hau, B., Tham, L. (2018): Mechanical pull-out capacity and root reinforcement of four native tree and shrub species on ecological rehabilitation of roadside slopes in Hong Kong. - Journal of Tropical Forest Science 25-38.

[26] Libohova, Z., Seybold, C., Wysocki, D., Wills, S., Schoeneberger, P., Williams, C., ... Owens, P. R. (2018): Reevaluating the effects of soil organic matter and other properties on available water-holding capacity using the National Cooperative Soil Survey Characterization Database. - Journal of Soil and Water Conservation 73(4): 411-421.

[27] Liu, C. L. C., Kuchma, O., Krutovsky, K. V. (2018): Mixed-species versus monocultures in plantation forestry: development, benefits, ecosystem services and perspectives for the future. - Global Ecology and Conservation 15: e00419.

[28] Martínez-Vilalta, J., Poyatos, R., Aguadé, D., Retana, J., Mencuccini, M. (2014): A new look at water transport regulation in plants. - New Phytologist 204(1): 105-115.

[29] Middleton, B. A. (2020): Trends of litter decomposition and soil organic matter stocks across forested swamp environments of the southeastern US. - PloS One 15(1).

[30] Moghaddam, E. R. (2014): Growth, development and yield in pure and mixed forest stands. - International Journal of Advanced Biological and Biomedical Research 2(10): 2725-2730.

[31] Montesinos-Navarro, A., Valiente-Banuet, A., Verdú, M. (2019): Mycorrhizal symbiosis increases the benefits of plant facilitative interactions. - Ecography 42(3): 447-455.

[32] Nerlich, K., Graeff-Hönninger, S., Claupein, W. (2013): Agroforestry in Europe: a review of the disappearance of traditional systems and development of modern agroforestry practices, with emphasis on experiences in Germany. - Agroforestry Systems 87: 475492.

[33] Neumann, R. B., Cardon, Z. G. (2012): The magnitude of hydraulic redistribution by plant roots: a review and synthesis of empirical and modeling studies. - New Phytologist 194(2): 337-352.

[34] Normaniza, O., Aimee, H., Ismail, Y., Tan, G. Y. A., Rozainah, M. Z. (2018): Promoter effect of microbes in slope eco-engineering: effects on plant growth, soil quality and erosion rate at different vegetation densities. - Applied Ecology and Environmental Research 16(3): 2219-2232.

[35] Oliveira, R. S., Dawson, T. E., Burgess, S. S., Nepstad, D. C. (2005): Hydraulic redistribution in three Amazonian trees. - Oecologia 145(3): 354-363.

[36] Osman, N., Barakbah, S. S. (2006): Parameters to predict slope stability—soil water and root profiles. - Ecological Engineering 28(1): 90-95.

[37] Osman, N., Barakbah, S. (2011): The effect of plant succession on slope stability. Ecological Engineering 37(2): 139-147.

[38] Pollen, N. (2007): Temporal and spatial variability in root reinforcement of streambanks: accounting for soil shear strength and moisture. - Catena 69(3): 197-205. 
[39] Pretzsch, H., Schütze, G. (2016): Effect of tree species mixing on the size structure, density, and yield of forest stands. - European Journal of Forest Research 135(1): 1-22.

[40] Prieto, I., Roldán, A., Huygens, D., del Mar Alguacil, M., Navarro-Cano, J. A., Querejeta, J. I. (2016): Species-specific roles of ectomycorrhizal fungi in facilitating interplant transfer of hydraulically redistributed water between Pinus halepensis saplings and seedlings. - Plant and Soil 406(1-2): 15-27.

[41] Rahman, H. A., Mapjabil, J. (2017): Landslides disaster in Malaysia: an overview. Health 8(1): 5871.

[42] Rahman, M., Lee, S. H., Ji, H. C., Kabir, A. H., Jones, C. S., Lee, K. W. (2018): Importance of mineral nutrition for mitigating aluminum toxicity in plants on acidic soils: current status and opportunities. - International Journal of Molecular Sciences 19(10): 3073.

[43] Saifuddin, M., Osman, N. (2014): Hydrological and mechanical properties of plants to predict suitable legume species for reinforcing soil. - Chinese Science Bulletin 59(35): 5123-5128.

[44] Saifuddin, M., Osman, N., Idris, R. M., Halim, A. (2016): The effects of pre-aluminum treatment on morphology and physiology of potential acidic slope plants. - Kuwait Journal of Science 43(2).

[45] Sharma, G. P., Singh, J. S., Raghubanshi, A. S. (2005): Plant invasions: emerging trends and future implications. - Current Science 88(5): 726-734.

[46] Smethurst, J., Briggs, K., Powrie, W., Ridley, A., Butcher, D. (2015): Mechanical and hydrological impacts of tree removal on a clay fill railway embankment. - Géotechnique 65(11): 869-882.

[47] Sorbino, G., Nicotera, M. V. (2013): Unsaturated soil mechanics in rainfall-induced flow landslides. - Engineering Geology 165: 105-132.

[48] Strickland, M. S., Rousk, J. (2010): Considering fungal: bacterial dominance in soilsmethods, controls, and ecosystem implications. - Soil Biology and Biochemistry 42(9): 1385-1395.

[49] Tang, A., Hughes, P. N., Dijkstra, T., Askarinejad, A., Brenčič, M., Cui, Y., ... Gentile, F. (2018): Atmosphere-vegetation-soil interactions in a climate change context; impact of changing conditions on engineered transport infrastructure slopes in Europe. - Quarterly Journal of Engineering Geology and Hydrogeology 2017-2103.

[50] Tyree, M. T., Patiño, S., Bennink, J., Alexander, J. (1995): Dynamic measurements of roots hydraulic conductance using a high-pressure flowmeter in the laboratory and field. Journal of Experimental Botany 46(1) 83-94.

[51] Van Hoorn, J. W. (1979): Determining hydraulic conductivity with the inversed auger hole and infiltrometer methods. - Proceedings of the International Drainage Workshop 16-20 May 1978, Wageningen, International Institute for Land Reclamation and Improvement.

[52] VanWoert, N. D., Rowe, D. B., Andresen, J. A., Rugh, C. L., Fernandez, R. T., Xiao, L. (2005): Green roof stormwater retention. - Journal of Environmental Quality 34(3): 1036-1044.

[53] Walkley, A., Black, I. A. (1934): An examination of the Degtjareff method for determining soil organic matter, and a proposed modification of the chromic acid titration method. - Soil Science 37(1): 29-38.

[54] Wang, J., Wang, P., Qin, Q., Wang, H. (2017): The effects of land subsidence and rehabilitation on soil hydraulic properties in a mining area in the Loess Plateau of China. - Catena 159: 51-59.

[55] Watanabe, T., Jansen, S., Osaki, M. (2005): The beneficial effect of aluminium and the role of citrate in $\mathrm{Al}$ accumulation in Melastoma malabathricum. - New Phytologist 773780 . 
[56] Watanabe, T., Jansen, S., Osaki, M. (2006): Al-Fe interactions and growth enhancement in Melastoma malabathricum and Miscanthus sinensis dominating acid sulphate soils. Plant, Cell and Environment 29(12): 2124-2132.

[57] White, P. J., George, T. S., Gregory, P. J., Bengough, A. G., Hallett, P. D., McKenzie, B. M. (2013): Matching roots to their environment. - Annals of Botany 112(2): 207-222.

[58] Yang, J. L., Zhang, G. L. (2011): Water infiltration in urban soils and its effects on the quantity and quality of runoff. - Journal of Soils and Sediments 11(5): 751-761.

[59] Yildiz, A., Graf, F., Rickli, C., Springman, S. M. (2018): Determination of the shearing behaviour of root-permeated soils with a large-scale direct shear apparatus. - Catena 166: 98-113.

[60] Zhang, Y., Chen, H. Y., Reich, P. B. (2012): Forest productivity increases with evenness, species richness and trait variation: a global meta-analysis. - Journal of Ecology 100(3): $742 \mathrm{e} 749$.

[61] Zhao, H., Yang, W., Wu, F., Tan, B. (2017): Mixed forest plantations can efficiently filter rainfall deposits of sulfur and chlorine in Western China. - Scientific Reports 7(1): 1-12.

[62] Zhao, B., Zhang, L., Xia, Z., Xu, W., Xia, L., Liang, Y., Xia, D. (2019): Effects of rainfall intensity and vegetation cover on erosion characteristics of a soil containing rock fragments slope. - Advances in Civil Engineering 2019.

[63] Zhen-li, L. (2016): Water content calculation and stability analysis of slope under persistent low-intensity rainfall infiltration. - Electronic Journal of Geotechnical Engineering 21: 1381-1399. 